\title{
Sonographic short-term follow-up after surgical decompression of the median nerve at the carpal tunnel: a single-center prospective observational study
}

\author{
Sueleyman Tas, MD, ${ }^{1}$ Frank Staub, MD, PhD, ${ }^{2}$ Thomas Dombert, MD, ${ }^{2}$ \\ Gerhard Marquardt, MD, PhD, ${ }^{1}$ Christian Senft, MD, PhD, ${ }^{1}$ Volker Seifert, MD, PhD, ${ }^{1}$ and \\ Stephan Duetzmann, MD, MSc ${ }^{1}$ \\ ${ }^{1}$ Department of Neurosurgery, University of Frankfurt; and ${ }^{2}$ Center for Peripheral Neurosurgery, Dossenheim-Heidelberg, \\ Germany
}

OBJECT Carpal tunnel syndrome causes increased cross-sectional area (CSA) of the median nerve, which can be assessed by high-definition ultrasonography. It is unclear today, however, whether high-definition ultrasonography may play a role in the postoperative period. This prospective study aimed to determine the natural history of the morphology of the median nerve at the carpal tunnel after surgical decompression assessed by high-definition ultrasonography.

METHODS Between October and December 2014, patients with suspected carpal tunnel syndrome who were referred to the authors' center for peripheral neurosurgery were prospectively enrolled and underwent pre- and postoperative ( 3 months) high-definition ultrasonography, electrophysiology, and clinical testing.

RESULTS Eighty-one patients were enrolled in the study, and 100\% were clinically better at the 3-month follow-up. The mean CSA decreased from $14.7 \pm 4.9 \mathrm{~mm}^{2}$ to $12.4 \pm 3.4 \mathrm{~mm}^{2}$ (mean $\pm \mathrm{SD}, \mathrm{p}<0.0001$ ). The mean distal motor latency decreased from $6.6 \pm 2.4 \mathrm{msec}$ to $4.8 \pm 1.0 \mathrm{msec}$ (mean $\pm \mathrm{SD}, \mathrm{p}<0.0001$ ). Ninety-eight percent of patients who were available for electrodiagnostic follow-up showed an improvement of the distal motor latency; only $80 \%$ had a reduction in the CSA.

CONCLUSIONS The authors present the second-largest series of patients with sonographic follow-up after surgical decompression of the carpal tunnel reported in the literature so far. This study, which showed a decrease in size of the median nerve after surgical decompression, suggests that the preoperative increase in median nerve CSA at the carpal tunnel may be due to compression and that enlargement of the median nerve is (partially) reversible.

http://thejns.org/doi/abs/10.3171/2015.6.FOCUS15216

KEY WORDS carpal tunnel syndrome; high-definition ultrasonography; carpal tunnel surgery

$\mathrm{C}$ ARPAL tunnel syndrome (CTS) causes increased cross-sectional area (CSA) of the median nerve, which can be assessed by high-definition ultrasonography. ${ }^{2,3,5,6,6,12,15-17}$ The compression in the carpal tunnel leads to edema and proliferation of fibrous tissue proximal to the compression site, which in turn results in swelling of the nerve and increased CSA in the 2D image. ${ }^{8,10}$

High-definition ultrasonography can thus be used for diagnosis of CTS with an accuracy that is equal to electrodiagnostic studies, ${ }^{10,13}$ it may give further information about an underlying pathological entity such as a ganglion cyst ${ }^{14}$ or it may provide information about muscular atrophy. ${ }^{9}$

It is unclear today, however, whether high-definition ul- trasonography may play a role in the postoperative period.$^{11}$ Patients who suffer from persistent or recurring symptoms may have a nerve that is still or again compressed and may benefit from a second decompression. If surgical decompression of the median nerve in the carpal tunnel results in normalization of the median nerve's CSA, this could help select patients who may benefit from a repeat surgery. On the other hand, if the nerve does not change morphologically postoperatively, then high-definition ultrasonography may not be helpful in the postoperative period to distinguish between patients whose nerve is still or again compressed and patients whose nerve is decompressed.

The goal of this prospective study was to determine the natural history of the morphology of the median nerve

ABBREVIATIONS CSA = cross-sectional area; CTS = carpal tunnel syndrome; $\mathrm{dmL}=$ distal motor latency .

SUBMITTED April 30, 2015. ACCEPTED June 16, 2015.

INCLUDE WHEN CITING DOI: 10.3171/2015.6.FOCUS15216. 
at the carpal tunnel after surgical decompression, as assessed by high-definition ultrasonography.

\section{Methods}

Institutional review board approval was obtained by the regional medical board committee (Landesärztekammer Baden Württemberg; F-2015-004). Between October and December 2014, patients with suspected CTS referred to our center for peripheral neurosurgery were prospectively screened for the study. Patients gave written informed consent and were prospectively enrolled.

The patients then routinely underwent standardized nerve conduction studies and subsequent sonographic evaluation. Clinical, sonographic, and electrophysiological parameters were assessed, as shown in Table 1. Nerve CSA and age were post hoc dichotomized into $\geq 12 \mathrm{~mm}^{2}$ or $<12 \mathrm{~mm}^{2}$ and $\geq 65$ years or $<65$ years to compare our findings with those of Vögelin et al., 15 who found a statistically significant difference in CSA reduction in these groups. Surgical decompression was then performed either in open fashion or endoscopically.

We performed a follow-up clinical, electrophysiological, and sonographic examination at baseline and at 3 months after surgical treatment.

\section{High-Definition Ultrasonography}

A real-time scanner (Toshiba Aplio MX with IStyle technology, Toshiba Medical Systems Europe) with a 19-MHz linear array transducer was used. Patients were seated in a chair with their arms extended and hands resting in a horizontal supinated position. The largest CSA of the median nerve was assessed at 2 positions: 1) distal to the carpal tunnel inlet between the pisiform bone and the scaphoid tubercle-i.e., the distal wrist flection crease (rascetta); and 2) in the forearm $5 \mathrm{~cm}$ proximal to the mentioned line, using manual tracing in serial transverse scans. We used only transverse scans to localize the median nerve and exclude relevant pathologies other than CTS. The largest CSA was determined by visual inspection during transverse scanning. In case of uncertainty, several transverse measurements were taken until the largest CSA was identified. Assessments of the largest CSA were performed twice and the arithmetic means of the 2 assessments were recorded. Examinations before and after treatment were performed in the same standardized manner.

\section{Statistical Analyses}

The means of categorical variables were compared using a nonparametric test such as the Mann-Whitney U-test. Correlation analysis was done as an exploratory analysis, and subsequent factors were then compared with univariate and multivariate ANOVA. Commercially available software was used (SPSS 22.0; IBM, Inc.).

\section{Results}

Overall, 81 patients were recruited for the study and a 3 -month clinical follow-up was obtained in $100 \%$. Sixtyseven patients were recruited for another sonographic follow-up. Basic demographic variables are shown in Table
TABLE 1. Summary of pre- and postoperatively assessed parameters in patients with CTS

\begin{tabular}{l}
\hline \multicolumn{1}{c}{ Variable } \\
\hline Clinical parameters assessed preop \\
\hline Age \\
\hline Sex \\
\hline Laterality \\
\hline Duration of symptoms ( $\leq 1$ yr vs $>1$ yr) \\
\hline Paresthesias (yes vs no) \\
\hline Numbness (yes vs no) \\
\hline Motor deficits (yes vs no) \\
\hline Atrophy (yes vs no) \\
\hline Typical brachialgia nocturna (yes vs no) \\
\hline Tendovaginitis stenosans (yes vs no) \\
\hline Diabetes (yes vs no) \\
\hline Clinical parameters assessed postop \\
\hline Scar pain \\
\hline Clinical improvement of preop symptoms \\
\hline Paresthesias (complete reduction vs partial reduction vs no change) \\
\hline Numbness (complete reduction vs partial reduction vs no change) \\
\hline Motor deficits (complete reduction vs partial reduction vs no \\
change) \\
\hline
\end{tabular}

2 . The majority of patients had open surgery (85\%). The main results for the clinical parameters are shown in Table 3. All of the patients improved clinically in the short-term follow-up. Most of the patients, however, had postoperative scar pain.

The main results of the sonographic and electrophysiological measurements are summarized in Table 4. Overall we observed a statistically significant reduction of the mean CSA of the median nerve proximally as well as distally 3 months after surgical decompression. Furthermore, distal motor latency (dmL) also improved statistically significantly after surgical decompression. Nevertheless, although all patients improved clinically, we did not see a reduction in the CSA in $20 \%$ of the patients. Whereas $98 \%$ of patients who were available for electrodiagnostic follow-up showed an improvement of the dmL, only $80 \%$ had a reduction in the CSA. An example of a postoperative reduction is shown in Fig. 1. The reduction of CSA was not statistically significantly correlated with the amount of reduction of the $\mathrm{dmL}$ (Pearson correlation coefficient $=$ $0.230, p=0.067$ ).

All statistically significant subgroup analyses are shown in Table 5. If the patient had a CSA that was $\geq 12$ $\mathrm{mm}^{2}$ preoperatively or if they were $<65$ years old, they had a significantly greater reduction of the percentage of their preoperative CSA $(p<0.001)$. Patients with motor deficits had statistically significantly longer preoperative $\operatorname{dmL}(10.5 \pm 2.8 \mathrm{msec}$ vs $6.5 \pm 2.3 \mathrm{msec} ; \mathrm{p}=0.021$ in multivariate analysis), but not a greater CSA $(p=0.124)$ or circumference $(\mathrm{p}=0.252)$.

Of all the other parameters that were assessed, we did not find a significant correlation between the parameters in the exploratory analysis (i.e., age, diabetes). We also did 
TABLE 2. Summary of basic demographic and preoperative variables in the population of patients with CTS

\begin{tabular}{lc}
\hline \multicolumn{1}{c}{ Variable } & Value (\%) \\
\hline Total no. of patients & $81(100 \%)$ \\
\hline Mean age in yrs, \pm SD & $56.9 \pm 16.4$ \\
\hline Male/female ratio & $1: 1.3$ \\
\hline Location of surgery & $51(63 \%)$ \\
\hline Lt & $30(37 \%)$ \\
\hline Rt & \\
\hline Duration of symptoms & $29(35.8 \%)$ \\
\hline$\leq 1$ yr & $52(64.2 \%)$ \\
\hline$>1$ yr & $74(91.3 \%)$ \\
\hline Paresthesias & $30(37.0 \%)$ \\
\hline Numbness & $2(2.5 \%)$ \\
\hline Weakness & $2(2.5 \%)$ \\
\hline Atrophy & $80(98.8 \%)$ \\
\hline Typical brachialgia nocturna & $12(14.8 \%)$ \\
\hline Concurrent tendovaginitis stenosans & 0 \\
\hline Concurrent hemodialysis & $8(9.9 \%)$ \\
\hline Concurrent diabetes & 79 \\
\hline No. w/ electrodiagnostic follow-up & 67 \\
\hline No. w/ sonographic follow-up & $69(85.2 \%)$ \\
\hline Open surgery & $12(14.8 \%)$ \\
\hline Endoscopic surgery & \\
\hline
\end{tabular}

not find any statistically significant difference between patients who underwent open and endoscopic surgery in any pre- and postoperative parameter, especially in the sonographic and electrophysiological results.

\section{Discussion}

Here we present the second-largest series of patients with sonographic follow-up after surgical decompression of the carpal tunnel that has been reported in the literature so far. For sonographic diagnosis of CTS, measurement of the CSA is the most reliable and common parameter. ${ }^{7}$ Further sonographic signs for CTS are palmar bowing and thickening of the flexor retinaculum and distal flattening of the median nerve, as well as loss of fascicular discrimination and reduced echogenicity. In addition to enlargement of the median nerve, distal flattening and especially reduction or even loss of fascicular texture were regularly seen in our patients; however, these parameters are less reliable because they are more difficult to quantify.

Most of our results are in line with the published literature (Table 6). ${ }^{1,11,15}$ Also, the subgroups of patients who are older ( $\geq 65$ years) and those who have a greater CSA $(\geq 12$ $\mathrm{mm}^{2}$ ) are in line with the published results from the Swiss group..$^{14}$ Variations in the results may be due to patient heterogeneity or different measurement protocols. This is in accordance with our results that patients with a larger preoperative CSA had a larger reduction in their CSA, even when corrected by using percentage of reduction related to preoperative values. Furthermore, those previous studies did not address whether endoscopic versus open surgery
TABLE 3. Summary of early clinical results in patients with CTS

\begin{tabular}{cc}
\hline Results at 3 Mos Postop & No. of Patients (\%) \\
\hline Clinical improvement & $81(100 \%)$ \\
\hline No improvement & $0(0 \%)$ \\
\hline Postop scar pain & $70(86.4 \%)$ \\
\hline Yes & $11(13.6 \%)$ \\
\hline No & $67(82.7 \%)$ \\
\hline Paresthesias & $7(8.6 \%)$ \\
\hline Complete resolution & $0(0 \%)$ \\
\hline Partial resolution & $7(8.6 \%)$ \\
\hline Persistent & \\
\hline No paresthesias preop & $24(29.6 \%)$ \\
\hline Numbness & $6(7.4 \%)$ \\
\hline Complete resolution & $0(0 \%)$ \\
\hline Partial resolution & $51(63 \%)$ \\
\hline Persistent & $2(2.5 \%)$ \\
\hline No numbness preop & $0(0 \%)$ \\
\hline Weakness & $0(0 \%)$ \\
\hline Complete resolution & $79(97.5 \%)$ \\
\hline Partial resolution & \\
\hline Persistent & \\
\hline No weakness preop & \\
\hline
\end{tabular}

can lead to a difference in postoperative CSA. In retrospective analysis, we could not find any difference.

In general, sonographic short-term follow-up seems to be inferior to electrodiagnostic short-term follow-up. Whereas $98 \%$ of patients who were available for electrodiagnostic follow-up showed an improvement, only $80 \%$ had a reduction in the CSA. This point was not addressed in the previous studies, which did not report the number of patients who did not improve sonographically.,11,15 The morphological improvement might be lagging behind the electrical improvement, when we hypothesize that the CSA will still decrease, which is unclear.

The large study of Smidt and Visser could not find any correlation between time of follow-up and reduction in CSA size, which could indicate that after 3 months the CSA will not decrease further. ${ }^{11}$ On the other hand, the study by Abicalaf et al. showed a time-dependent reduction, but only until 3 months postoperatively, when that study was terminated. ${ }^{1}$

TABLE 4. Main results in 81 patients with CTS*

\begin{tabular}{cccc}
\hline Parameter & Preop & $\begin{array}{c}\text { 3 Mos } \\
\text { Postop }\end{array}$ & p Value† \\
\hline $\begin{array}{c}\text { Mean CSA of median nerve at } \\
\text { wrist, in } \mathrm{mm}^{2}\end{array}$ & $14.7 \pm 4.9$ & $12.4 \pm 3.4$ & $<0.0001$ \\
\hline $\begin{array}{c}\text { Mean CSA of median nerve at } \\
\text { forearm, in mm } \mathrm{mm}^{2}\end{array}$ & $9.9 \pm 2.8$ & $8.0 \pm 1.6$ & $<0.0001$ \\
\hline Mean dmL, in msec & $6.6 \pm 2.4$ & $4.8 \pm 1.0$ & $<0.0001$ \\
\hline
\end{tabular}

* Values are expressed as the mean \pm SD. All parameters showed significant improvement postoperatively. Only $80 \%$ of the patients showed an improvement in their CSA.

$\dagger$ A paired t-test was used for statistical analysis. 


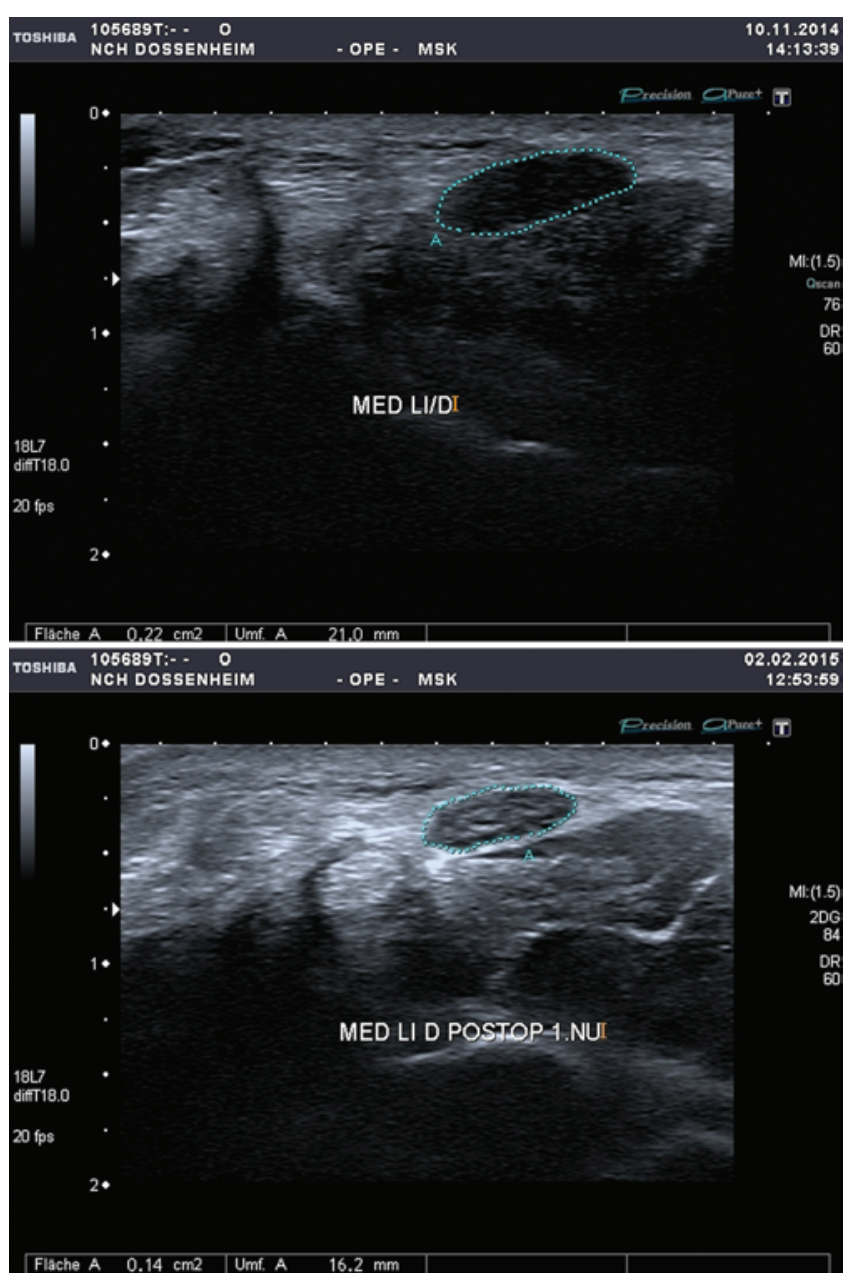

FIG. 1. Example of a postoperative reduction of a CSA in 1 patient, as assessed by high-definition ultrasonography. Upper: Preoperative image. Lower: Postoperative image obtained after 3 months. Of note is a significant change in texture of the nerve that highlights the typical change from a dark nerve to the better visibility of the internal fascicular structure.

Several authors have studied the value of high-definition ultrasonography for the diagnosis of CTS. ${ }^{5,6,16,17} \mathrm{In}$ addition to contributing to the diagnostic workup of patients with suspected CTS, sonographic examination allows noninvasive detection of aberrations. ${ }^{4,9,10}$ In our investigation, however, electrodiagnostic studies seemed to

TABLE 5. Statistically significant findings of the subgroup analyses in patients with CTS

\begin{tabular}{lcc}
\hline Subgroup & Mean CSA Reduction, in $\%$ of Preop Value* & p Value \\
\hline Age & & \\
\hline$\geq 65 \mathrm{yrs}$ & $5.6 \% \pm 26 \%$ & 0.046 \\
\hline$<65 \mathrm{yrs}$ & $17.4 \% \pm 19 \%$ & \\
\hline Preop CSA & & \\
\hline$\geq 12 \mathrm{~mm}^{2}$ & $20.2 \% \pm 18 \%$ & \\
\hline$<12 \mathrm{~mm}^{2}$ & $-1.5 \% \pm 22 \%$ & \\
\hline${ }^{*}$ Values are expressed as the mean $\pm \mathrm{SD}$. & \\
$\dagger$ &
\end{tabular}

TABLE 6. Comparison of results of the current study with the data available in the literature

\begin{tabular}{lcccc}
\hline & No. of & & \multicolumn{2}{c}{ Mean CSA in $\mathrm{mm}^{2 *}$} \\
\cline { 3 - 5 } Authors \& Year & Participants & Follow-Up & Preop & Postop \\
\hline Vögelin et al., 2010 & 58 & 6 mos & $12.4 \pm 3.3$ & $10.0 \pm 2.7$ \\
\hline Abicalaf et al., 2007 & 20 & 3 mos & $15.0 \pm 2.1$ & $8.6 \pm 1.6$ \\
\hline $\begin{array}{l}\text { Smidt \& Visser, } \\
2008\end{array}$ & 79 & 19 mos & 14.0 & 11.5 \\
\hline $\begin{array}{l}\text { Present study } \\
\text { Presen }\end{array}$ & 67 & 3 mos & $14.7 \pm 4.9$ & $12.4 \pm 3.4$ \\
\hline * Values for CSA are expressed as the mean \pm SD. & &
\end{tabular}

be more sensitive in picking up preoperative deficits-our patients with motor deficits had statistically significantly longer preoperative $\mathrm{dmL}(10.5 \pm 2.8 \mathrm{msec}$ vs $6.5 \pm 2.3$ msec; $\mathrm{p}=0.021$ in multivariate analysis), but not greater CSA $(p=0.124)$ or circumference $(p=0.252)$.

Our stratified analyses provided little evidence that decreases in CSA depend on baseline characteristics other than the actually measured CSA at baseline. Whereas one study found an almost statistically significant correlation between CSA and clinical improvement, ${ }^{15}$ we could not find any correlation. In our particular study this is due to the high number of patients with clinical improvement. This could change in the longer term, for example if patients develop late recurrences.

We found a $100 \%$ improvement rate in the first 3 months after release. This is better than in most of the large published series and might be surprising given the reader's personal experience. However, release of the carpal tunnel is a worthwhile procedure and if the diagnosis is correct (i.e., a typical clinical presentation and pathological electrophysiological parameters including an increased $\mathrm{dmL}$ ), a high degree of improvement can be achieved. The 100\% improvement found in this study might be related to the relatively small number of patients, participation bias, and a short follow-up. In larger patient series, participants with persistent complaints are likely.

The strengths of our study include a prospective design in unselected consecutive patients, the standardized protocol, experience of the surgeons (F.S. and T.D.), and the large number of patients. The major limitations of our study are its short-term follow-up and the nonrandomized nature, which may have resulted in confounding based on indication. Furthermore, the exceptionally good clinical results hinder the assessment of a relationship between general clinical outcome and sonographic follow-up. We are not able to answer the question whether a good sonographic reduction can go along with a bad clinical outcome.

\section{Conclusions}

Our study, which showed a decrease in size of the median nerve after surgical decompression, suggests that the preoperative increase in median nerve CSA at the carpal tunnel may be due to compression and that enlargement of the median nerve is (partially) reversible.

\section{References}

1. Abicalaf CA, de Barros N, Sernik RA, Pimentel BF, Braga- 
Baiak A, Braga L, et al: Ultrasound evaluation of patients with carpal tunnel syndrome before and after endoscopic release of the transverse carpal ligament. Clin Radiol 62:891-896, 2007

2. Bianchi S, Martinoli C, Abdelwahab IF: High-frequency ultrasound examination of the wrist and hand. Skeletal Radiol 28:121-129, 1999

3. Bianchi S, Martinoli C, Sureda D, Rizzatto G: Ultrasound of the hand. Eur J Ultrasound 14:29-34, 2001

4. Gofeld M, Bristow SJ, Chiu S, Kliot M: Preoperative ultrasound-guided mapping of peripheral nerves. J Neurosurg 119:709-713, 2013

5. Martinoli C, Bianchi S, Cohen M, Graif M: [Ultrasound of peripheral nerves.] J Radiol 86:1869-1878, 2005 (Fr)

6. Padua L, Pazzaglia C, Caliandro P, Granata G, Foschini M, Briani C, et al: Carpal tunnel syndrome: ultrasound, neurophysiology, clinical and patient-oriented assessment. Clin Neurophysiol 119:2064-2069, 2008

7. Peer S, Bodner G (eds): High-Resolution Sonography of the Peripheral Nervous System. Berlin: Springer, 2008

8. Rempel D, Dahlin L, Lundborg G: Pathophysiology of nerve compression syndromes: response of peripheral nerves to loading. J Bone Joint Surg Am 81:1600-1610, 1999

9. Simon NG, Ralph JW, Lomen-Hoerth C, Poncelet AN, Vucic S, Kiernan MC, et al: Quantitative ultrasound of denervated hand muscles. Muscle Nerve [epub ahead of print], 2014

10. Simon NG, Ralph JW, Poncelet AN, Engstrom JW, Chin C, Kliot M: A comparison of ultrasonographic and electrophysiologic 'inching' in ulnar neuropathy at the elbow. Clin Neurophysiol 126:391-398, 2015

11. Smidt MH, Visser LH: Carpal tunnel syndrome: clinical and sonographic follow-up after surgery. Muscle Nerve 38:987991, 2008

12. Tagliafico A, Resmini E, Nizzo R, Bianchi F, Minuto F, Ferone $\mathrm{D}$, et al: Ultrasound measurement of median and ulnar nerve cross-sectional area in acromegaly. J Clin Endocrinol Metab 93:905-909, 2008

13. Visser LH, Smidt MH, Lee ML: High-resolution sonography versus EMG in the diagnosis of carpal tunnel syndrome. J Neurol Neurosurg Psychiatry 79:63-67, 2008

14. Vögelin E, Mészàros T, Schöni F, Constantinescu MA: Sonographic wrist measurements and detection of anatomical features in carpal tunnel syndrome. ScientificWorldJournal 2014:657906, 2014

15. Vögelin E, Nüesch E, Jüni P, Reichenbach S, Eser P, Ziswiler HR: Sonographic follow-up of patients with carpal tunnel syndrome undergoing surgical or nonsurgical treatment: prospective cohort study. J Hand Surg Am 35:1401-1409, 2010

16. Wong SM, Griffith JF, Hui ACF, Tang A, Wong KS: Discriminatory sonographic criteria for the diagnosis of carpal tunnel syndrome. Arthritis Rheum 46:1914-1921, 2002

17. Ziswiler HR, Reichenbach S, Vögelin E, Bachmann LM, Villiger PM, Jüni P: Diagnostic value of sonography in patients with suspected carpal tunnel syndrome: a prospective study. Arthritis Rheum 52:304-311, 2005

\section{Disclosure}

The authors report no conflict of interest concerning the materials or methods used in this study or the findings specified in this paper.

\section{Author Contributions}

Conception and design: Duetzmann, Staub. Acquisition of data: Tas, Staub, Dombert. Analysis and interpretation of data: Duetzmann. Drafting the article: Duetzmann. Critically revising the article: Staub, Marquardt, Senft. Statistical analysis: Duetzmann. Administrative/technical/material support: Staub, Dombert, Marquardt, Seifert. Study supervision: Staub, Dombert.

\section{Correspondence}

Stephan Duetzmann, Department of Neurosurgery, Goethe University Hospital Frankfurt, Schleusenweg 2-16, 60528 Frankfurt, Germany. email: stephan.duetzmann@gmail.com. 